\title{
Lactic Acid Promotes Cell Survival by Blocking Autophagy of B16F10 Mouse Melanoma Cells under Glucose Deprivation and Hypoxic Conditions
}

\author{
Taisuke Matsuo,* Shun Daishaku, and Yasuyuki Sadzuka \\ Division of Advanced Pharmaceutics, Department of Clinical Pharmaceutical Sciences, School of Pharmacy, Iwate \\ Medical University; 2-1-1 Nishitokuta, Yahaba-cho, Shiwa-gun, Iwate 028-3694, Japan. \\ Received November 23, 2018; accepted February 8, 2019
}

In solid tumors, cancer cells are exposed to microenvironment stress, including hypoxia and insufficient nutrients. An acidic microenvironment in tumors is facilitated by the increase in synthesis of lactic acid; this is known as Warburg effect. We previously showed that B16F10 melanoma cells were induced autophagic cell death by glucose-deprivation stress, and lactic acid suppressed the cell death through the inhibition of autophagy. In this study, effects of lactic acid on cell death of B16F10 cells under hypoxic and glucose-depleted double stress conditions were investigated. The double stress promoted autophagic cell death earlier than glucose-depleted stress alone. Lactic acid repressed the double stress-induced cell death by inhibiting autophagy. These results suggest that lactic acid serves for cell survival under microenvironmental stress conditions in B16F10 melanoma cells.

Key words lactic acid; hypoxia; glucose deprivation; autophagy; cell death

\section{INTRODUCTION}

The environment of solid tumors is low-nutrition and hypoxia due to the rapid proliferation of tumor cells and immature vascularization. ${ }^{1,2)}$ Glucose is catabolized into lactic acid to enhance aerobic glycolysis, known as Warburg effect, and causes the tumor microenvironment to be acidic. ${ }^{3-6)}$ We previously demonstrated that glucose deprivation induced autophagic cell death of B16F10 melanoma cells, but the acid conditions, which are derived from lactic acid or $\mathrm{pH}$-adjustment by $\mathrm{HCl}$, inhibited the cell death mechanism. ${ }^{7)}$ In vivo, tumor cells are exposed to not only glucose deprivation but also hypoxia. The effects of lactic acid on the double stress of glucose deprivation and hypoxia remain unclear. In this study, we revealed the role of lactic acid in autophagic cell death under double stress conditions in B16F10 melanoma cells.

\section{MATERIALS AND METHODS}

Cell Culture, Double Stress Induction, and the Effect on Autophagy Preparation of B16F10 mouse melanoma cells (B16F10 cells), the cell culture, treatment, and analytical methods were previously described. ${ }^{7)}$ For induction of the double stress of glucose deprivation and hypoxia, B16F10 cells were seeded at $2 \times 10^{5}$ cells $/ \mathrm{mL}$ medium into 24 -well plates. After $24 \mathrm{~h}$, the growth medium was changed to a glucosefree medium. The cells were maintained under $20 \%$ or $1 \% \mathrm{O}_{2}$ conditions for $16 \mathrm{~h}$. The dead cell ratio and viable cell number were calculated by cell counting. Autophagy inhibitor 3-methyladenine $(5 \mathrm{mM})$ and LY294002 $(25 \mu \mathrm{M})$ was used to analyze the effects of the double stress on autophagy.

Effect of Lactic Acid on B16F10 Cells under the Double Stress Conditions To analyze the effects of lactic acid on the double-stressed B16F10 cells, they were treated with lactic acid $(20 \mathrm{mM})$-supplemented glucose-free medium for $16 \mathrm{~h}$.

Lactic acid-free medium supplemented with sodium lactate $(20 \mathrm{mM})$ was used as a control. In addition, HCl-adjusted Dulbecco's modified Eagle's medium (DMEM), which is a same condition as $20 \mathrm{mM}$ lactic acid DMEM ( $\mathrm{pH}$ 6.9), was used to analyze the effects of acidic environment without lactic acid.

Western Blot Analysis B16F10 cells were cultured in DMEM without glucose under 20 or $1 \% \mathrm{O}_{2}$ conditions at $16 \mathrm{~h}$. Western blot analysis using anti-LC3B and anti- $\beta$-actin antibodies was performed, as previously described. ${ }^{7,8)}$ The ratio of

A

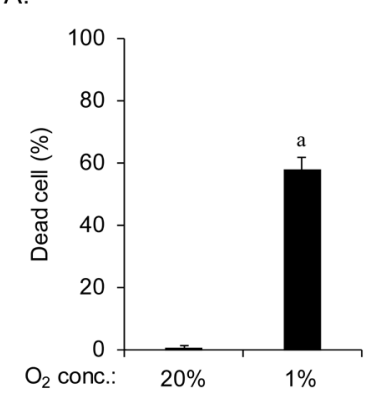

C.

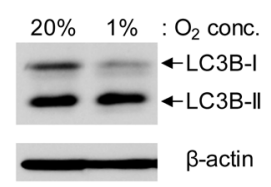

B.

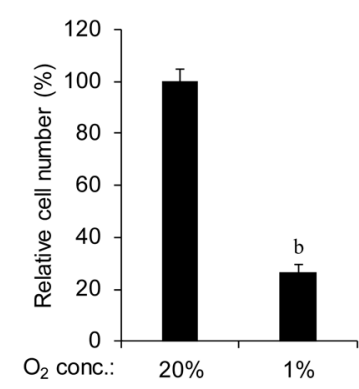

* To whom correspondence should be addressed. e-mail: tmatsuo@iwate-med.ac.jp 
A.

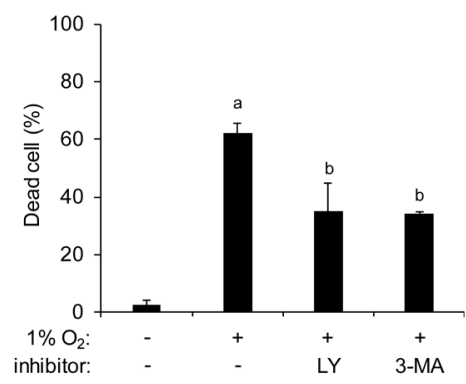

B.

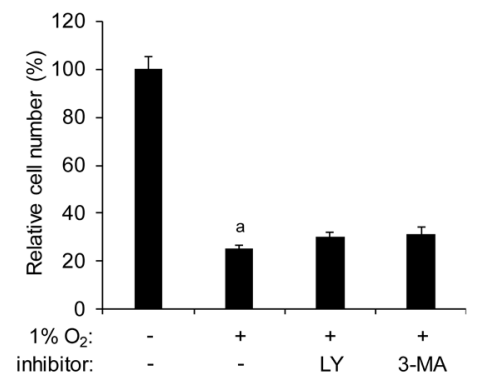

c.

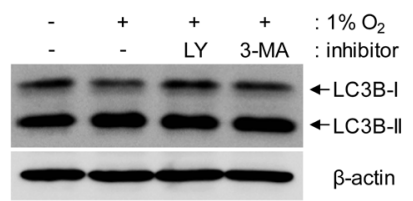

Fig. 2. Inhibition of Autophagy Suppresses Cell Death in B16F10 Cells under the Stress of Glucose Deprivation and Hypoxic Conditions

(A) Dead cell rate and (B) relative cell number of B16F10 cells were calculated $16 \mathrm{~h}$ after treatment with $25 \mu \mathrm{M}$ LY294002 or $5 \mathrm{mM} \mathrm{3-MA}$. The bars represent the mean \pm S.D. of triplicate counts. ${ }^{a} p<0.001$ (comparison to $20 \% \mathrm{O}_{2}$ conditions), ${ }^{\mathrm{b}} p<0.001$ (comparison to $1 \% \mathrm{O}_{2}$ conditions without treatment of autophagy inhibitor) indicate significant differences (Tukey-Kramer test). $1 \% \mathrm{O}_{2}(-)$ and LY indicate $20 \% \mathrm{O}_{2}$ conditions and LY294002 treatment, respectively. (C) LC3B conversion in B16F10 cells was examined at $16 \mathrm{~h}$ after treatment of LY294002 or 3-MA.

A.

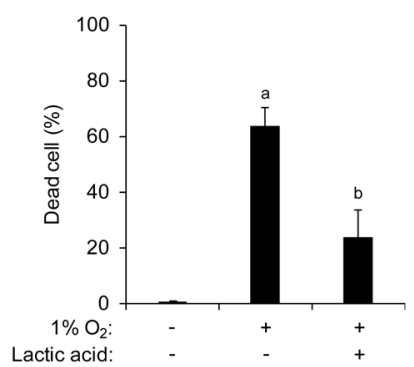

C.
B.

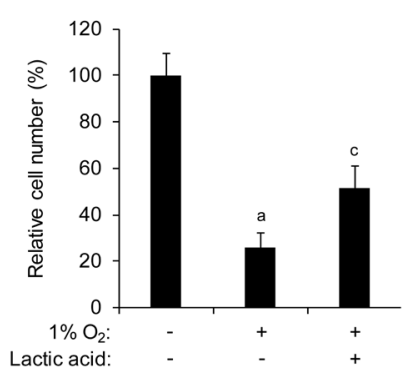

A.

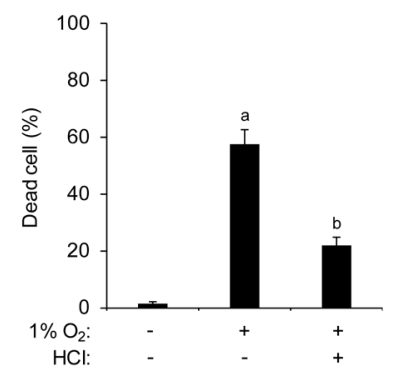

B

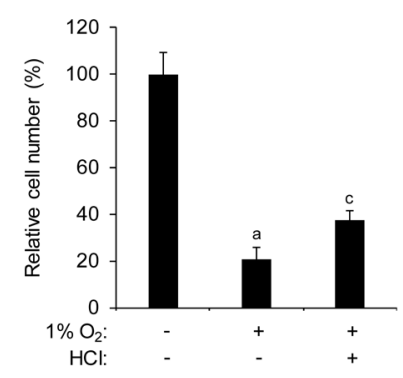

C.

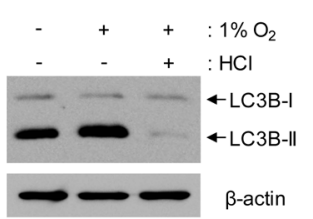

Fig. 4. HCl-Adjusted Acidic Condition Suppresses Cell Death and Autophagy under Glucose Deprivation and Hypoxic Conditions

B16F10 cells were cultured in DMEM ( $\mathrm{pH}$ 6.9) adjusted by $\mathrm{HCl}$ under glucose deprivation and $1 \% \mathrm{O}_{2}$ conditions for $16 \mathrm{~h}$. (A) Dead cell rate and (B) relative cell number were analyzed. The results represent the mean \pm S.D. in triplicate. ${ }^{\mathrm{a}} p<0.001$ (compared to $20 \% \mathrm{O}_{2}$ without $\mathrm{HCl}$ conditions), ${ }^{\mathrm{b}} p<0.001$ and ${ }^{\mathrm{c}} p<0.05$ (compared to $1 \% \mathrm{O}_{2}$ without $\mathrm{HCl}$ conditions) indicate significant differences (Tukey-Kramer test). (C) LC3B conversion in B16F10 cells was examined by Western blot analysis with anti-LC3B antibody after $16 \mathrm{~h}$ of double stress.

poxia on B16F10 cells were compared to the effects of the single stress of glucose deprivation. The double stress of glucose deprivation and hypoxia induced more cell death at $16 \mathrm{~h}$ than the glucose deprivation stress alone (Figs. 1A, B). Western blot analysis showed about 2.0-fold higher conversion of LC3B-I to LC3B-II, an autophagy marker, in cells under double stress conditions than in those under glucose deprivation alone (Fig. 1C). Treatment of B16F10 cells under glucose deprivation and hypoxic conditions with autophagy inhibitor LY294002 and 3-MA suppressed cell death (Figs. 2A, B). The ratio of LC3BII/LC3B-I in B16F10 cells treated with LY294002 or 3-MA

Effects of the double stress of glucose deprivation and hy- 
was about 40 or $10 \%$ lower than untreated-cells under glucose deprivation and $1 \% \mathrm{O}_{2}$ conditions (Fig. 2C).

The effects of lactic acid on the double stress-inducing autophagic cell death in B16F10 cells were examined. As expected, lactic acid inhibited cell death and increased survival cell number (Figs. 3A, B). The LC3B conversion in B16F10 cells treated with $20 \mathrm{mM}$ lactic acid conditions was about $60 \%$ lower than untreated-cells under glucose deprivation and $1 \%$ $\mathrm{O}_{2}$ conditions (Fig. 3C). Furthermore, acidic DMEM adjusted by $\mathrm{HCl}$ without lactic acid also inhibited cell death under the double stress conditions (Figs. 4A, B). Western blot analysis showed that $\mathrm{LC} 3 \mathrm{~B}$ conversion of $\mathrm{B} 16 \mathrm{~F} 10$ cells cultured in DMEM adjusted by $\mathrm{HCl}$ was over $90 \%$ decrease compared to $1 \% \mathrm{O}_{2}$ without $\mathrm{pH}$-adjustment by $\mathrm{HCl}$ (Fig. 4C).

\section{DISCUSSION}

In this study, we analyzed the effects of lactic acid on B16F10 cells that were subjected to the microenvironment stresses of glucose deprivation and hypoxia. Autophagy is induced when cells are subjected to stresses such as nutrient deprivation. Intracellular proteins and organelles are degraded and recycled as an alternative energy source. Therefore, autophagy is important for cell survival. ${ }^{9)}$ However, prolonged autophagy induces self-digestion and triggers cell death. ${ }^{10,11)}$ In tumor cells, the role of autophagy in response to microenvironmental stress including glucose deprivation and hypoxia has been reported both cell survival and cell death. ${ }^{12-16)} \mathrm{We}$ previously showed that glucose deprivation stress induced cell death by autophagy in B16F10 cells. ${ }^{7)}$ In this study, the addition of hypoxic stress to glucose depletion induced autophagic cell death more than glucose depletion stress alone (Fig. 1). Although inhibition of autophagy by LY294002 and 3-MA suppressed cell death, recovery of survival cell number did not occur (Fig. 2). It is possible that the double stress represses cell growth independent of autophagy. In addition, lactic acid inhibited both cell death and autophagy (Fig. 3). Medium without lactic acid, supplemented with sodium lactate at the same concentration as lactic acid, was used as a control. In addition, $\mathrm{HCl}$-adjusted conditions without lactic acid also inhibited the double stress-induced cell death and autophagy (Fig. 4). The results suggest that the effect of lactic acid is acidification of the extracellular environment, rather than as an alternative energy source.

In conclusion, we demonstrated that lactic acid is necessary for survival of B16F10 cells upon induction of autophagic cell death by the double stress inflicted by glucose deprivation and hypoxia. The results provide insight into a mechanism employed by tumor cells in order to survive under stress condi- tion of the in vivo microenvironment.

Conflict of Interest The authors declare no conflict of interest.

\section{REFERENCES}

1) Brown JM, Giaccia AJ. The unique physiology of solid tumors: opportunities (and problems) for cancer therapy. Cancer Res., 58, 1408-1416 (1998)

2) Denko NC. Hypoxia, HIF1 and glucose metabolism in the solid tumour. Nat. Rev. Cancer, 8, 705-713 (2008).

3) Vander Heiden MG, Cantley LC, Thompson CB. Understanding the Warburg effect: the metabolic requirements of cell proliferation. Science, 324, 1029-1033 (2009).

4) Griffiths JR. Are cancer cells acidic? Br. J. Cancer, 64, 425-427 (1991).

5) Kato Y, Ozawa S, Miyamoto C, Maehata Y, Suzuki A, Maeda T, Baba Y. Acidic extracellular microenvironment and cancer. Cancer Cell Int., 13, 89 (2013).

6) Hirschhaeuser F, Sattler UG, Mueller-Klieser W. Lactate: a metabolic key player in cancer. Cancer Res., 71, 6921-6925 (2011).

7) Matsuo T, Sadzuka Y. Extracellular acidification by lactic acid suppresses glucose deprivation-induced cell death and autophagy in B16 melanoma cells. Biochem. Biophys. Res. Commun., 496, 1357-1361 (2018).

8) Matsuo T, Fujiwara A, Nakamura K, Sadzuka Y. The effects of vitamin B6 compounds on cell proliferation and melanogenesis in B16F10 melanoma cells. Oncol. Lett., 15, 5181-5184 (2018).

9) Yang ZJ, Chee CE, Huang S, Sinicrope FA. The role of autophagy in cancer: therapeutic implications. Mol. Cancer Ther., 10, 15331541 (2011).

10) Gozuacik D, Kimchi A. Autophagy as a cell death and tumor suppressor mechanism. Oncogene, 23, 2891-2906 (2004).

11) Maiuri MC, Zalckvar E, Kimchi A, Kroemer G. Self-eating and self-killing: crosstalk between autophagy and apoptosis. Nat. Rev. Mol. Cell Biol., 8, 741-752 (2007).

12) Morselli E, Galluzzi L, Kepp O, Vicencio JM, Criollo A, Maiuri MC, Kroemer G. Anti- and pro-tumor functions of autophagy. Biochim. Biophys. Acta, 1793, 1524-1532 (2009).

13) Chen Y, Liersch R, Detmar M. The miR-290-295 cluster suppresses autophagic cell death of melanoma cells. Sci. Rep., 2, 808 (2012).

14) Sato K, Tsuchihara K, Fujii S, Sugiyama M, Goya T, Atomi $Y$, Ueno T, Ochiai A, Esumi H. Autophagy is activated in colorectal cancer cells and contributes to the tolerance to nutrient deprivation. Cancer Res., 67, 9677-9684 (2007).

15) Azad MB, Chen Y, Henson ES, Cizeau J, McMillan-Ward E, Israels SJ, Gibson SB. Hypoxia induces autophagic cell death in apoptosiscompetent cells through a mechanism involving BNIP3. Autophagy, 4, 195-204 (2008).

16) Tan Q, Wang M, Yu M, Zhang J, Bristow RG, Hill RP, Tannock IF. Role of autophagy as a survival mechanism for hypoxic cells in tumors. Neoplasia, 18, 347-355 (2016). 